Architektur des Mittelalters

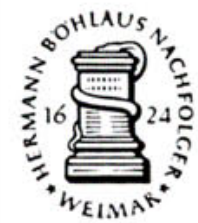





\title{
Architektur des Mittelalters
}

Funktion und Gestalt

\author{
Herausgegeben von
}

Friedrich Möbius und ERnSt Schubert

1983

HERMANN BOHLAUS NACHFOLGER, WEIMAR 
Mit 239 Abbildungen

(C) 1983 by Hermann Böhlaus Nachf., Weimar LSV 8124

$272-140 / 208 / 83$

Printed in the German Democratic Republic

Satz und Druck: VEB Druckhaus Köthen

Bindearbeiten: Druckhaus „Maxim Gorki“ Altenburg

Klischeeherstellung: Interdruck, Leipzig

Gestaltung: Ralph Dehncke, Jena

L.-Nr. 2576

Bestell-Nr. 7956720

DDR 62,- M 